\title{
THE QUILEUTE APPROACH \\ TO LANGUAGE REVIVAL PROGRAMS
}

*J. Sandefur

During the past decade educational policy towards Aboriginal languages has changed dramatically. The institution of the Federal Government's bilingual/bicultural policy was a complete turnaround from past policies that attempted to stamp out all vestiges of Aboriginal culture.

The bilingual policy has aided, at least in principle, the rise of Aboriginal identity. The desire to proclaim one's Aboriginality and strengthen, or in some cases reconnect, one's tie with his Aboriginal heritage is no longer stigmatised.

Aboriginal groups can broadly be classified according to their relation to Aboriginal culture ${ }^{1}$ :

1. Those groups that still retain strong culture, even among the youngest of children.

2. Those groups in which much of their culture is 'dying' -the adults have it but the children are not learning it.

3. Those groups that have lost direct connections with most of their Aboriginal culture.

The present educational policy affects each of these three groups in slightly different ways. For the first group the policy functions in a sense like an insurance policy stating that education will not (or at least should not) be detrimental to their culture and cause a breakdown in the transmission channel.

For the second group the present policy holds hope of turning around the trend of decline in the transmission of culture to the young generations. The policy (theoretically) provides for closing the gap between the older generations who know and have, and the younger generations who do not.

* John Sandefur, Summer Institute of Linguistics, P.O.Berrimah, Northern Territory.

1 I am using Aboriginal culture here in a very broad and undefined sense, mach the same way as it is typically used colloquially. 
For the third group the bilingual policy offers little direct help in the recovery of their lost heritage. It does, however, at the policy level remove the stigma from wanting to be Aboriginal and desiring to stop denying one's heritage. At the classroom level it provides a time slot in which reflections on one's cultural heritage can be made.

Many schools have been requested by Aboriginal communities to teach their children 'culture'. When asked for specifications as to what should be taught, the responses usually include 'language'.

The main function of language in the broader Australian community is most often seen as being a vehicle of communication. In order to get on in today's Australia it is believed one has to be able to communicate in 'standard' English. Other languages are generally viewed as being hindrances to progressive communication. The smaller the group a language serves, the more restrictive it is considered to be.

But language is not just a vehicle for every day communication - it is a medium of cultural transmission. One cannot come to a full understanding of a specific language without looking at the culture in which it occurs because language itself is part of culture.

Thus it is that when a language dies, it is not just words and sounds that disappear, but culture as well. There are many Mara and Ngandi people living in the Roper River area of the Northern Territory, but only a handful of older people can fluently speak these two languages.

In talking about the death of the Mara language, it was not the language that was referred to as dying but the people as dying to their language, someone else said: ${ }^{1}$

Ngandi is not spoken any more. They don't speak

Ngandi here. Their whole race has died out.

Because of the important role that language plays in the transmission of culture and the vital function of culture as forming the essence of a group's existence, the dying of the language is seen not as the death of the language but in some sense as the death of the people, the death of the 'race'.

1 This is a translation of the comment from Kriol. 
The bilingual education policy, at least as it was implemented in the Northern Territory, recognizes four types of bilingual/bicultural programs:

a) Programs in which initial literacy is in the Aboriginal language of the children.

b) Programs in which the Aboriginal 1anguage of the children is used in early instruction but initial literacy is in English.

c) 'Revival' programs where the Aboriginal language is no longer spoken by the children.

d) 'Elective' programs where children (usually in the older grades) are given opportunity to work in their own language.

Three of these programs ( $a, b$ and $d$ ) have in common the fact that the children speak the language and (at least with a and $b$ ) the school does some teaching in the language.

The revival type program, however, is distinctive because the children do not speak the language and the school teaches the language. ${ }^{1}$ It is this revival type program that I wish to address my thoughts to.

\section{REVIVAL PROGRAMS}

It appears that the majority of Aboriginal parents want their children and grandchildren to speak their traditional language. This seems to be a universal of human psychology. Man does not want to see his language lost. Because of this many schools in Aboriginal communities have been faced with the request that the traditional language (or languages) be taught to the children.

Many schools have started revival programs, but few have met with success. In many cases an older person who still speaks the language is given a time slot several days each week during which he is expected to teach the children the language. Often the class is held on the school grounds outside the natural context of the language, though excursions to a more suitable location may be made as part of the lesson.

I see Nugent (1979) for a description of an innovative language program at Jervis Bay, N.S.W. 
The language teacher typically has had no formal teacher training and may not be given any instruction or help in planning the lessons. The class is often simply turned over to him. Since he learned the language it is assumed he knows how to teach the language.

At the opposite end of the scale are a few schools which have employed the aid of a linguist to develop a thorough and well laid out language course. ${ }^{1}$ In these schools a serious attempt is made to work out a second-language teaching syllabus for the language teacher.

Between these two extremes are programs in which the language teacher has some teacher training and is given some basic help in preparing a set of lessons using second-language teaching principles.

Very few revival programs have been successful in teaching children to speak the traditional language fluently. One of the major causes for failure - as many involved in such programs are well aware - is that a language cannot be taught adequately in the classroom alone. If any degree of fluency is to be gained by the students, the language must be used outside the classroom. Parents must use the language with the children at home, and the children must be motivated to use the language at home also.

This latter point is probably the most important. In many communities the adults do use the traditional language to the children at home, but the children do not use it back to them. The environment for learning the language is there, but the motivation on the part of the children is not.

In such a situation the children passively learn the language. In the natural environment they gain a 'hearing' ability in the language. It has been observed - but not specifically studied that in some communities (e.g. Bamyili, N.T., and Fitzroy Crossing, W.A.) that school leavers sometimes 'learn' to speak their traditional language. Once they have moved away from the childhood/school environment and into the adult world, the motivation for speaking a traditional language naturally develops in some people.

It seems to be a presupposition that when a school undertakes a revival program it must of necessity strive for total natural fluency in the language. Without ever raising the question, it is assumed that is what the Aboriginal parents want. 
As far as I am aware, no study has been made as to why Aboriginal parents and elders want their traditional language taught to the children who are no longer speaking it. (And it should be noted here that in many communities there are two and three generations who do not speak the traditional language.)

In 1980, Alan Cole ${ }^{1}$ met with seventeen leaders of the major clans taking part in the Groote Eylandt dance festival. The leaders represented clans from northern Queensland, Arnhem Land, the Kimberleys and Central Australia. One of the issues Cole discussed with the clan leaders was the importance for a particular tribal group of retaining its own traditional language.

The leaders responded with three main thoughts: the first, which is common throughout the world, was that the language has sentimental value. Secondly, there was a sense that the introduction of any new language as the language of the home represents a gap at that particular point between the generations. This problem has been well documented among migrants in Australia. The third was "a very strong feeling that the persistence of the language was necessary for the retention of the bulk of the culture of the past."

Cole summarised by saying that while emotional and various other matters such as the problem of communication entered in,

the great basic thought was language enshrines and exemplifies the culture and without the persistence of the language as a living form many of the cultural affinities with the past would be lost forever. [This was the view] of the vast majority of the seventeen clan leaders.

It appears to me that Aborigines largely desire to maintain their traditional languages:

a) as a link with their heritage,

b) as a means of cultural continuity,

c) as a symbol of group identity,

d) as a portable proof of Aboriginality. 
I would suggest that if these are the legitimate reasons for which Aborigines want revival programs, then total grammatical control of the language is not necessary. There is an alternative pedagogical approach to reviving a traditional language that has been successfully applied among the Quileute Indians in the northwest of the United States. This approach is one of relexification ${ }^{2}-$ replacing the lexicon or vocabulary of one language with that of another.

\section{THE QUILEUTE APPROACH}

In the early 1970s linguist J.V. Powell (1973a, 1973b) was hired by the Quileute tribe of La Push, Washington, to teach the tribal language, which was known by only about ten elders, to young Quileutes, all of whom could only speak English.

The Quileute language is a complex language with over 200 suffix forms. Powell prepared lessons to teach a normal language course employing phonetic practice, grammatical exercises, dialogues and drills of various types. His assumption was that the goal of the program was to work toward fluency in Quileute and thus resuscitate Quileute as an everyday spoken language.

After a week the program was, in Powell's terms, "a shambles". The class had neither the time nor the interest to master a system so different from their everyday speech. So Powell reconsidered his approach. His teaching technique was sound as long as he assumed the goal was total, grammatically natural Quileute fluency. But it was this premise which he found to be incorrect and disabling to the program.

The Quileutes wished to know their language because it was their heritage, because it fostered a sense of their culture, and because it served as a sign of the group and of Indianness. None of these reasons required native fluency or even reasonable virtuosity.

1

What I refer to as relixifaction, Powell (1973a, 1973b) refers to as pidginization. If the grammar of the students' mother tongue is fully retained and only new words substituted, then the process is relexification. If, however, the grammar is 'standardised' or simplified, then more than relexification is involved. With Quileute as described by Powell, the English grammar of the students was simplified; hence the new quileute involved simplification (or pidginization as Powell referred to it) rather than simply relexification. 
So Powell restructured the course so it included only Quileute vocabulary, drills providing practice in pronunciation of non-English sounds, and exercises in which the students inserted as many Quileute words as they knew.

The Quileute phonetics was gradually attacked and no stigma was attached to being unable to pronounce the difficult sounds. Quileute grammar was anglicized. For example, instead of indicating plural by the difficult reduplication of the Quileute word (such as ka'ki'la for the plural of káña 'stone'), they simply added $-s$ as in English (hence kárhas). The tenses were formed by adding -ed for past and the Quileute word kitaxay 'going' for future:

$$
\begin{array}{ll}
\text { e.g. I rá•las.. } & \text { I eat. } \\
\text { I rá•lał́ed. } & \text { I ate. } \\
\text { I kitax́áy ra.lał. } & \text { I will eat. }
\end{array}
$$

Increasing vocabulary size allowed rapid progress from, for example,

$$
\begin{aligned}
& \text { Give me half that candy. } \\
& \text { to Give me half that zape?. } \\
& \text { to Hes me half sal zaper. } \\
& \text { to Hes me tałara sa? zaper. }
\end{aligned}
$$

The final sentence is a lopsided sentence according to the original Quileute grammar, but it is a functional statement full of real Quileute words that could be understood by those who were learning the language.

Students compiled word lists of the Quileute names for flora and fauna, implements, articles of clothing, body parts, numbers and other elements of the natural world and indigenous cultural surroundings. Indian mythological heroes sprang back to life. The ethnographic elements of native medicine, mythology, art, cooking and crafts generated as much curiosity as the terms for individual items. The students were not satisfied with simply knowing the names of things. Outside the student group a groundswell of new respect for the tribal language resulted in consideration of a rule by the tribal council that all signs in the village be bilingual, Quileute and English. 
The Quileute language program would have stagnated and foundered with the impossible and unnecessarily inflated goal of total, grammatical, natural language fluency. That was an impossible goal because of limitations of student time and interest, and an unnecessary goal because no one had reasons for studying the language that nothing less than fluency would satisfy.

The new version of Quileute could be acquired in the time the students were prepared to devote to the project. It generated interest by allowing immediate colloquial use of what was learned rather than deflating interest when it became apparent that years would be required to effectively learn to speak the language proper$1 y$ and grammatically.

\section{RELEXIFICATION IN AUSTRALIA}

It is not suggested here that the Quileute relexification approach is' appropriate for all revival program situations in Australia. Where the traditional language is still actively spoken in the community, it would not only be inappropriate but probably unacceptable to the adults as well.

For communities or Aboriginal groups in which the language has totally died, the Quileute relexification approach is definitely applicable. It may be the only practical and potentially successful approach for such communities. Likewise, for some communities in which only a few older people can still remember the language, it may be the only viable approach.

Relexification is not, in itself, an unnatural linguistic phenomenon. To the contrary, it is fairly common right across the world. It occurs naturally in many situations, especially where one language group comes into contact with another with linguistic and cultural interaction between them.

The English spoken, for example, in southern Ireland in areas that used to be Gaelic speaking contains a large number of Gaelic words. These Gaelic words carry with them a particular nuance necessary for the transmission of values which are not values of Anglo-Saxon people speaking Anglo-Saxon speech. ${ }^{1}$

1 Personal communication from Alan Cole, 14 September 1981. 
Relexification occurs to varying degrees in traditional Australian Aboriginal languages. It is well known that in some areas when a person dies the name of the person is no longer used. Anyone else with the same name changes his name. He, in fact, relexifies his name, substituting another word for the one he had previously used.

Many traditional Aboriginal 1anguages have undergone varying degrees of relexification upon contact with English. Bani and Klokeid (1972), for example, describe the Western Torres Strait language Yagar Yagar as having two versions - the original which they refer to as Langgus and a modern version spoken by the younger generations which they call Modern Langgus. Modern Langgus is grammatically identical to Langgus, but the lexicon includes many words borrowed from English. Modern Langgus is in effect a partially relexified version of Langgus.

Similarly, in the South-West of Western Australia, Douglas (1976) coined the term Neo-Nyunar to designate a 'modern' version of the traditional Njunar. Neo-Nyunar is in a sense a relexified version of Njunar. ${ }^{1}$ The speakers themselves, however, use only the one term Njunar to designate both varieties of the language.

These two examples are, of course, relexification in the direction of English. English words have been substituted for the traditional words. The relexification approach to revival programs is essentially the same but operates in the opposite direction. Starting with the everyday speech of the school children, traditional language words are substituted for their everyday speech words.

Relexification in this direction takes place naturally in some Aboriginal communities. Speakers of Aboriginal English and Kriol 'borrow' words from traditional languages. One means of defining dialect boundaries is according to the 'language' words that are used in Aboriginal English or Kriol. In many cases Kriol speaking children have a thorough knowledge of traditional language names for flora and fauna, but lack a knowledge of verbs and have no ability to put together complete sentences in the traditional language.

1 More than relexification is involved in that the grammar of Njunar has also been largely replaced. 
What the Quileute relexification approach does is to build upon the existing knowledge of the children by substituting new words in the grammar of the children's everyday speech. Once the process has been started in the classroom, the children should be able to continue without overt instruction from the school.

I would like to illustrate the concept of the Quileute relexification approach to language revival programs by using Ngandi.

\section{THE NGANDI EXAMPLE}

Ngandi is a language from southern Arnhem Land. It has been described by Heath (1978), who claims that "there are probably about six people who speak Ngandi well now." Heath's principal informant has since died, leaving maybe five persons who can fluently speak Ngandi. A11 of them also speak Kriol, which is now the mother tongue of most Ngandi tribesmen.

Ngandi is a prefixing language. Each complete verb begins with a pronominal prefix that marks the pronominal category of the subject for all verbs as well as the object for transitive verbs. There are some 135 pronominal categories, each with its own prefix. In addition to the pronominal prefixes there are two dozen other types of verb prefixes.

Ngandi verbs also take suffixes to indicate tense/aspect/mood categories, of which there are ten. Regular verbs fall into six classes, each with its own set of suffixes. In addition to these six classes there are a number of irregular verbs, not to mention irregular prefix and suffix forms. Thus, to gain fluency in Ngandi verbs, one has to control not only the verb roots but also more than 200 prefixes and suffixes.

Ngandi nouns characteristically occur with noun-class prefixes, of which there are nine. In many cases it is possible to determine to which class a noun belongs from the form of the noun or its meaning, but in many other cases there is no clue in the word itself. The noun-class for such words has to be learned individually. Nouns are also marked for case, of which there are ten, by suffixes. In addition, there are a host of other prefixes and suffixes applicable to the noun.

A person has to control at least four morphemes or 'parts of words' to begin to be able to use, for example, the transitive verb, gu 'eat'. To make the simple statement 'I ate some' in Ngandi, requires, at the minimum, knowing which pronominal prefix to use for the object, which pronominal prefix to use for the subject, which 
form of the verb root to use, and which suffix to use to indicate tense/aspect. For example:

$$
\begin{aligned}
& \text { Barma-pa-no-n. 'I ate some!" } \\
& \begin{array}{r}
\text { object - subject - verb - tense } \\
\text { root }
\end{array}
\end{aligned}
$$

Although the verb in Ngandi can express the whole sentence, other words are often used in the sentence as well. These often also require a knowledge of prefixes and suffixes. For example:

$$
\begin{aligned}
& \text { Ma-niť-ug barmananon gaya. 'I ate some food.' } \\
& \text { noun - food - object verb I } \\
& \text { class }
\end{aligned}
$$

To use the verb fluently, a person has to learn a host of prefixes and suffixes as well as changes in the verb root. For example:

$\begin{array}{ll}\text { Barmaganog. } & \text { 'I ate some.' } \\ \text { Barmaganutini. } & \text { 'I am eating some.' } \\ \text { Barmanagunun. } & \text { 'I will eat some.' } \\ \text { Barmagargunuy. } & \text { 'We (inclusive) will eat some.' } \\ \text { Barmañargunun. } & \text { 'We (exclusive) will eat some.' } \\ \text { Barmabagunun. } & \text { 'They will eat some.' } \\ \text { Nigurabagunuy. } & \text { 'They will eat one.' }\end{array}$

When a verb of a different class is used, another set of suffixes is required. For example, ramg 'spear'.
Nigurabaramdi.
'They speared one.'
Nigurabaramonani.
'They are spearing one'
Ṇigựabaṛamğan.
'They will spear one.'

A revival program for Ngandi that sets as its goal the attainment of complete grammatical fluency will of necessity be extremely complex and time consuming. There is little prospect of such a program for school children being successful. 
The Quileute relexification approach begins with the known everyday speech of the school children. In the case of Ngandi children that is Kriol. For example:
Ai bin dagat sambala.
'I ate some.'

To begin to use the Ngandi verb for 'eat', the child simply needs to learn the basic root form without any alterations and substitute it into his Kriol sentence. For example:
Ai bin go sambala.
'I ate some.'

The Kriol tense/aspect system, which the child already controls, can be used. For example:
Ai gojo sambala.
'I am eating some.'
Ai garra go sambala.
'I will eat some.'

Other verbs can be learned and substituted without difficulty. For example:
Ai bin ramğ sambala.
'I speared some.'
Ai bin baț sambala.
'I got some.'
Ai bin na sambala.
'I saw some.'

Pronouns and other words can be learned at an individual's own pace and progressively substituted. For example:
Ai bin nạ sambala.
'I saw some.'
yaya bin ṇa sambala
'I saw some.'
yaya bin ṇa bowoṇi.
'I saw some.'
Jaya bin ṇa bowoṇi gił.
'I saw some food.'
Jaya bin na bowoṇi ṇigun.
'I saw some honey.'
yaya bin na bowoṇi mabarawu.' I saw some boats.'

Such a procedure enhances the chances of success for the child by reducing embarrassing situations in which the child does 
not control the Ngandi forms by allowing him to use his everyday speech and only substitute the Ngandi words he knows. Whether he says yaya bin na bowoni mabarawu or yaya bin na sambala mabarawu because he does not control bowoni will not be a handicap. He will still be able to express what he wants to say with enough Ngandi content to be considered to be speaking modern Ngandi. He will not be misunderstood because he is unable to form the 'right' Ngandi construction, since everyone knows the Kriol construction he relies upon. Such sentences would not, of course, be 'correct' constructions by Ngandi grammar standards, but they would be functional statements full of real Ngandi words.

\section{CONCLUSION}

What I have suggested here is that a new look be taken at 'revival' language programs. It is suggested that in some cases the desires - the true underlying desires - of the adults do not warrant longterm, complex language teaching programs that strive to achieve full natural fluency in the traditional language.

I have suggested that there is a viable alternative to the traditional type of language revival program. The Quileute relexification approach provides for a readily devised, easily learned modern version of the traditional language that puts success within the grasp of virtually any group of students and their language teacher.

I am indebted to Eve Fesl for her constructive comments on an earlier draft of this paper.

\section{REFERENCES}

Bani, E. and Klokeid, T.J., 1972: Kala Yagau Langgus - Yagar Yagar: The Western Torres Strait Language. Canberra, A.I.A.S. MS

Douglas, W.H., 1976: The Aboriginal Languages of the South-West of Australia. 2nd edition. Canberra; A.I.A.S.

Heath, J., 1978: Ngandi Grammar, Texts, and Dictionary. Canberra, A.I.A.S.

Nugent, A., 1979: The incorporation of near extinct Aboriginal languages into the curriculum of Jervis Bay Primary School. The Aboriginal Child at School, 7:5, 20-28. 
Powe11, J.V., 1973a: Pidgins as an alternative in teaching moribund Canadian Indian languages. Paper presented to the Canadian Sociology and Anthropology Association, Kingston, Ontario. MS.

Powe11, J.V., 1973b: Raising Pidgins for fun and profit: a new departure in language teaching. Paper presented to the Pacific Northwest Conference on Foreign Languages, Rosario Resort, Washington. MS.

Richards, E., 1982: Walmajarri language and the Noonkanbah community. In J. Bell (Ed.) Aboriginal Languages Association, $A$ Collection of Papers Presented at the Second Meeting of the A.L.A. pp.43-46. Alice Springs, Institute for Aboriginal Development.

\section{4 \\ SUBSCRIPTIONS}

SUBSCRIPTIONS FOR 1984 ARE NOW DUE $\$ 10,00$

PLEASE MAIL YOUR SUBSCRIPTION BEFORE THE END OF THE SCHOOL YEAR IF POSSIBLE, THIS WILL FACILITATE UPDATING THE MAILING LIST IN TIME FOR YOU TO RECEIVE THE FEBRUARY/MARCH ISSUE, 